\title{
The Effectiveness of Virtual Reality-Based Simulation in Health Professions Education Relating to Mental Illness: A Literature Review
}

\author{
Wai Hin Wan', Angie Ho Yan Lam² \\ ${ }^{1}$ School of Public Health, The University of Hong Kong, Hong Kong, China \\ ${ }^{2}$ School of Nursing, The University of Hong Kong, Hong Kong, China \\ Email: abrahamw@hku.hk, angielam@hku.hk
}

How to cite this paper: Wan, W.H. and Lam, A.H.Y. (2019) The Effectiveness of Virtual Reality-Based Simulation in Health Professions Education Relating to Mental Illness: A Literature Review. Health, 11, 646-660.

https://doi.org/10.4236/health.2019.116054

Received: May 5, 2019

Accepted: June 2, 2019

Published: June 5, 2019

Copyright $\odot 2019$ by author(s) and Scientific Research Publishing Inc. This work is licensed under the Creative Commons Attribution International License (CC BY 4.0).

http://creativecommons.org/licenses/by/4.0/

\begin{abstract}
The proliferation of Virtual Reality-based tools has led to its increased usage in the field of education over the last decades owing to its increasingly realistic simulation and greater control over the 3D simulated environment. The unique features of Virtual Reality (VR) simulation can provide learners with a hazard-free simulated environment allowing limitless failure attempts. Yet, good quality research to verify the effectiveness of VR simulation in training students of the health profession is still lacking. This literature review focuses on the effectiveness of virtual reality-based simulation in enhancing health profession students' empathetic attitude relating to mental illness. Four databases were searched from January 1, 2007 to December 31, 2018. Of 1034 articles identified eligible in the databases, a total of 6 articles have met the criteria for inclusion in this review. Findings suggested that there is a clear relationship between VR simulation and an improvement on users' empathy, attitudes, and knowledge relating to mental Illness. With the unique characteristic of experiential learning of VR simulation, there is a potential development of the VR simulation on empathy and attitude in healthcare education. Also, VR stimulation is found having a larger impact on the users' empathy of users with a healthcare background compared to those without. Future studies should include more in-depth examination on the effect on the specificity of empathy and attitude of people with healthcare background, and in teaching a wider range of mental illnesses such as depression and general anxiety disorder.
\end{abstract}

\section{Keywords}

VR Simulation, Health Professions Education, Mental Illness, Virtual Reality Exposure 


\section{Introduction}

\subsection{What Is Virtual Reality (VR)?}

The advent of the term VR dated back to the 1960s [1] when the mechanical device Sensorama Simulator was first introduced [2]. Macpherson and Keppell [3] defined VR as "a state produced in a person's mind that can, to varying degrees, occupy the person's awareness in a way similar to that of real environments". The key features of VR include a three-dimensional imaging which can either be a real-world object or an abstract world, the ability of active interaction with the virtual environment, and a visual and auditory feedback [4]. VR environments can be further classified as immersive and non-immersive. Immersive VR involves frequent interactivity and a peripheral device such as head-mounted displays (HMDs) or a room where the walls are projection screens (CAVE) while non-immersive VR involves computer monitor and little interaction with the mouse [5].

With advancement in VR hardware, the current display technology can provide users visual displays with haptic and multi-sensory feedback via output devices like HMDs [6]. The mobile HMDs including the Google Cardboard and Gear VR were developed to provide simple casing for users to carry their smartphones as displays and data processors [6]. By utilizing the computer-generated 3D real-time environments with the output devices, users can experience in three aspects from the physical world, which are actual geographic distance elimination, genetically generated physical distances elimination, and temporally coordinate ability [7]. After the invention of a new generation of HMDs from Oculus Rift [8], VR simulation became more accessible for research and education purposes. Consequently, the New Media Consortium Horizon report in 2016 had predicted that the VR technology will be adopted in higher education field in two to three years [9].

\subsection{Experiential Mental Health Training for Health Professionals}

An integrative review has revealed the paucity of adequate mental health educational preparation among general health professionals who are required to deliver different level of care to patients of mental illness in various healthcare settings [10]. Studies revealed that general healthcare professionals had significant shortcomings in knowledge and attitude pertaining to psychiatric disorders, which hinder the provision of adequate and appropriate services [10] [11]. While the ubiquitous stigmatizing attitude among health professionals was attributed to their experience [12], experiential mental health training with supervised clinical experience were found to facilitate the effectiveness of the programs [10]. The effectiveness can be explained by Kolb's Experiential Learning Theory of which, in the cycle of diverging, assimilating, converging, and accommodating [13], learners can react to their individual perceptions of experiences under the philosophical principle of constructionism [14]. Studies in psychology have shown an increase in the application of Experiential Learning 
Theory in psychometrics [13].

\subsection{VR Simulation in Mental Health Education among Student Health Professions}

Simulation-based activities entail the creation of a "real" situation which immerses learners in an experience while developing new skills, new attitudes, or new ways of thinking in a safe environment [15]. It engages students in an experiential learning process with the goal of achieving cognitive, psychomotor and affective domain of learning [15]. It has expanded exponentially in healthcare education recently to diversify the range of clinical and nonclinical skills, including physician clinical skills, midwifery skills, laparoscopic surgery training or understanding of mental illness [16]-[22]. The most common simulation methods adopted in undergraduate curriculum of mental health training are the use of standardized or simulated patients and voice-hearing simulations, so as to enhance students' therapeutic communication technique and reduce fear [23]. Although healthcare simulation is identified as a powerful tool a change in practice among student in the health profession [24], the conventionally adopted simulation were critiqued for lacking realism and attention to organizational contexts [25] [26]. The proliferation of VR tools has increased usage in the field of education over the last decades owing to its greater ecologically valid stimulus presentation and tighter control of 3D simulated environment [27]. With the highly manipulative virtual environments, VR technology is suggested to have high flexibility in providing systematic experiential training that optimizes the degree of transfer of training to individual's reality perceptions [28]. VR simulations may, therefore, provide a more realistic experiential learning environment in the highly flexible and programmable virtual environment to healthcare learners than the conventional simulation [28]. Pantelidis [29] suggested that VR simulation of teaching scenarios can be adopted when "information visualization is needed, manipulating and rearranging information, using graphic symbols, so it can be more easily understood". While visualization of hallucinations has been effective in reducing stigma of schizophrenia [30], VR simulation has the advantage of transforming not only hallucination, but also other psychotic symptoms and patient's experience into high level of personal efficacy and self-reflectiveness, and engaging multiple senses which is suitable for mental health education [31] [32]. Nonetheless, on the grounds that studies have shown medical students and health professionals having a higher level of perceived stigmatization and lacking knowledge related to mental illness, VR simulation may emerge as a novel education approach in mental health training. This research gap has provoked the sine qua non on further review on the impact of VR simulation on mental health education.

\section{Review Methods}

\subsection{Search Strategy}

The timeframe chosen was from January 1, 2007 to December 31, 2018, as the 
analysis aimed at reviewing the effectiveness of virtual reality-based simulation in mental health education. Searches were performed in PsycINFO, CINAHL, Education Resources Information Center (ERIC) and Pudmed on January 4, 2019 which included the terms "Medical Education", "Clinical Education", "Health Education" and "Mental Health Education", and "Virtual Reality Simulation", "Virtual Reality" and "Mental Disorders", "Mental Illness", Mental Illnesses" and in the title or abstract with the language restriction of English. In addition to the electronic databases, references list of all selected articles were manually searched to identify further relevant articles and earlier seminal sources.

\subsection{Study Selection}

To be eligible for inclusion for full text final review, studies had to: 1) Targeted experimental studies to evaluate the effect of virtual reality simulation in mental health education; 2) Quantitative or qualitative data for the result analysis; and 3) Published in English. Publications with no title or abstract, and book chapter, and reviews, and editorials will be excluded. Studies that did not include virtual reality simulation training and mental illness related training in the result analysis were excluded.

\subsection{Types of Participants}

The inclusion criteria for participants in this review were all students at varying levels of enrollment studying health-related subjects/programs, or health care professionals. Besides, participants with no fulfillment of inclusion criteria will also be included as compassion group in this review to examine the difference in feasibility and effectiveness between those of health care backgrounds and non-healthcare backgrounds.

\subsection{Types of Intervention}

Interventions of analysis were the interventions adopting VR simulation mental health education training as the primary component to examine the effectiveness of VR simulation to the health professionals.

\subsection{Types of Outcomes}

The outcomes include students' empathy, attitudes and knowledge. The most frequently endorsed fundamental techniques in practice for psychotherapists were relationship-oriented for instance empathy, understanding and attitudes towards psychiatric clients [33]. To measure the effectiveness of the VR simulation education relating the mental illness, the current review explored the opportunity of VR simulation used as an educational tool to enhance students' empathy and attitude towards mental illness patients, and academic-based learning on the symptoms or the technical skills on patients caring.

\subsection{Data Extraction}

The following data were extracted from each article to standardize the reviewing 
process. The defined extractions were: Study and participant characteristics (e.g. study design, study purpose, sample size and recruitment method); primary results of the measurements on subjects' knowledge, attitudes or empathy; limitations; and the conclusion of the authors drew on the effectiveness of virtual reality-based simulation in healthcare education to enhance students' knowledge, attitudes, and empathy relating to mental illness.

\section{Results}

\subsection{Search Results}

After the removal of duplicate articles from 1038 articles that were searched via PsychINFO, CINAHL, ERIC and PubMed, 1034 articles were identified eligible in the databases that were published since January 2007. After the title and abstract selection in accordance to the exclusion criteria, 758 articles which obviously meet the exclusion criteria were excluded and 31 full-text publications were retrieved and reviewed for final selection. Of these, 25 articles were excluded according to the exclusion criteria with 6 articles which are four single-case research studies and two quasi-experimental studies meeting the inclusion criteria (Figure 1).

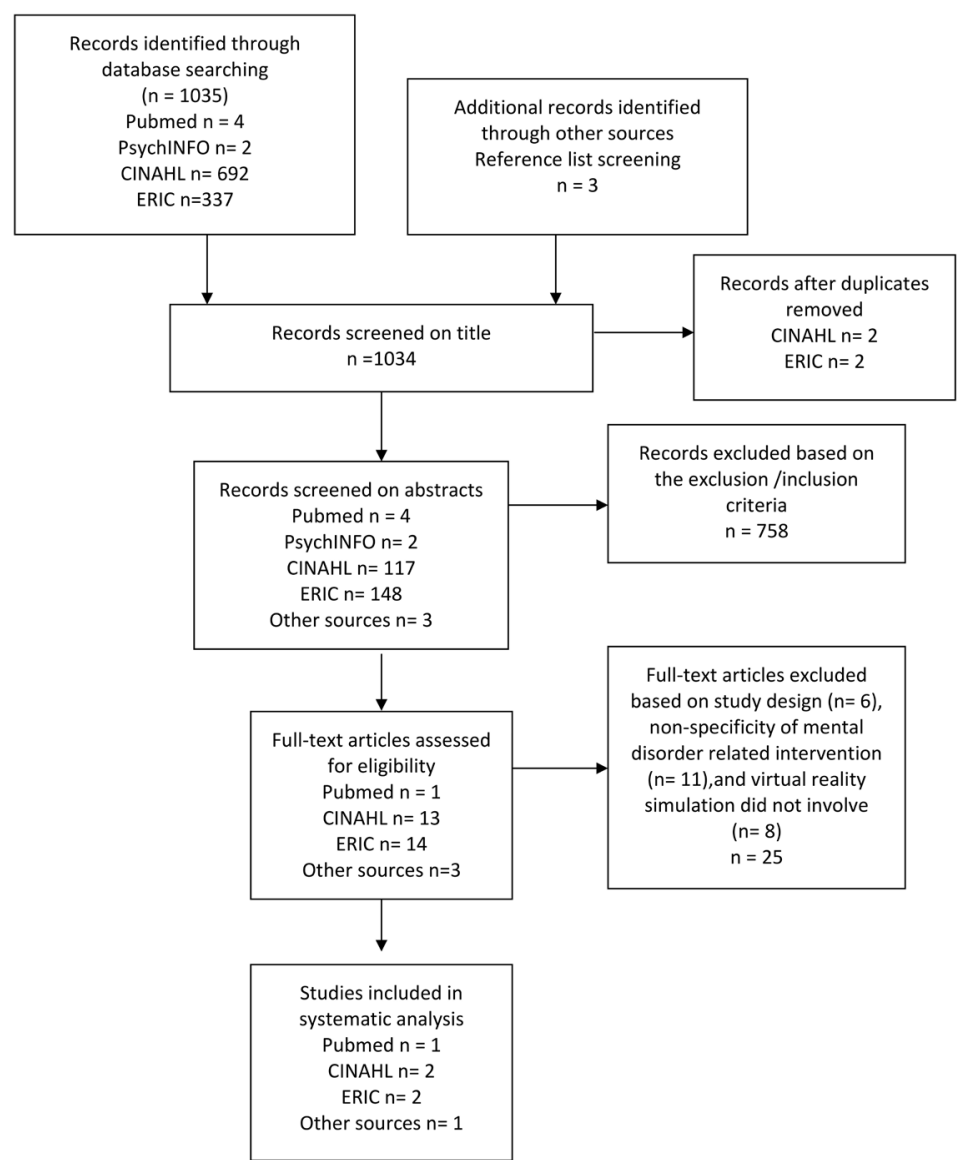

Figure 1. Search and inclusion process flowchart of studies to include in systematic review. 


\subsection{Characteristics of Studies}

Sample sizes of participants ranged from 80 to 800 while the subject groups of the articles are two for nursing students [34] [35], one for medical and other health professions students [36], one for informal caregivers [37], one for teachers [38], and one for general public and psychology undergraduate [39].

Among the 6 selected articles to answer the research question, most of the articles [34] [35] [36] [38] [39] $(n=5)$ confirmed the association between users' exposure to VR simulation and users' improvement in knowledge, attitudes, or empathy. Only one article [37] has concluded that no significant differences were found between exposure to VR simulation and users' empathy and sense of competence (Table 1).

The literature identified that the majority of the research focused on the impacts of VR simulation on users' knowledge and empathy relating to mental illness while users' attitude has been examined in two studies only. Findings are presented below with brief discussion and analysis.

\subsection{Users' Empathy Gain}

Preston [40] suggested that empathy is defined by most current researchers as a subject having "a similar emotional state to an object as a result of the accurate perception of the object's situation or predicament". Meanwhile, enhancing empathy is the increase of ability in relating the feelings perceived from others with our own experience and inferring what others are going through [41].

Of the three studies [36] [37] [39] that examined users' empathy, two of them [36] [39] have confirmed the association between VR simulation and heightened empathy while the remaining [37] found no significant differences. Meanwhile, only the study from Dyer et al. examined the impacts of VR simulation on health profession students.

The study conducted by Dyer and colleagues [36] examines the empathy gain of medical students towards Alzheimer's disease patients with cognitive and physical degeneration experience via VR simulation, in which 800 showed increased empathy for the Alzheimer's disease. Subjective reports from participants indicated that VR simulation could be an effective training tool for mental health professionals in empathy gain due to its capability of simulating high levels of emotional experience of the "stigmatized other" with immersive environment. This is consistent with the study conducted by Formosa and colleagues [39], which recruited fifty participants with a psychology undergraduate degree $(n=3)$ and individuals from the general public $(n=47)$ and utilized a custom-made VR simulation which provided users the immersive story-driven replication of positive schizophrenic and other psychotic disorder symptoms such as auditory and visual hallucinations, and paranoid delusional thoughts. Findings from the participants' pre and post-test scores exhibited significant enhancement of empathetic understanding towards patients with schizophrenia and other psychotics $(\mathrm{p}<0.001)$. The features of high fidelity and users' buy-in of VR simulation had found to be associated with the empathy gain scores. 
Table 1. Characteristics of the selected articles on effectiveness of VR simulation in medical education to enhance users' knowledge, attitudes, and empathy.

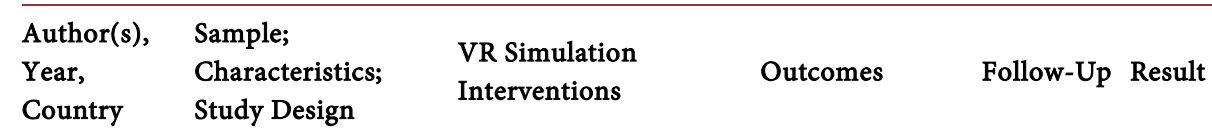

Sweigart

et al., 2014,

United

States

$\mathrm{N}=800 ;$ Nursing

students; Non

control study
Simulating student nurse and patient avatars interviews in immersive VR clinic with interactive reception area and two examination rooms for mental health assessments
Perception of the reality of the experience, Preparation for actual clinical experiences
Students with no virtual interview experience generated an average of 7.36 urogenital-sexual system assessment questions with human patients; Students who had completed an avatar patient interview in the virtual environment posed an average of 10.06 questions

(range, 0 - 24; $\mathrm{p}=0.001$ ).

Ninety percent of the students agreed that the virtual environment experience helped them to develop a care plan for subsequent psychiatric patients at the health care agency.

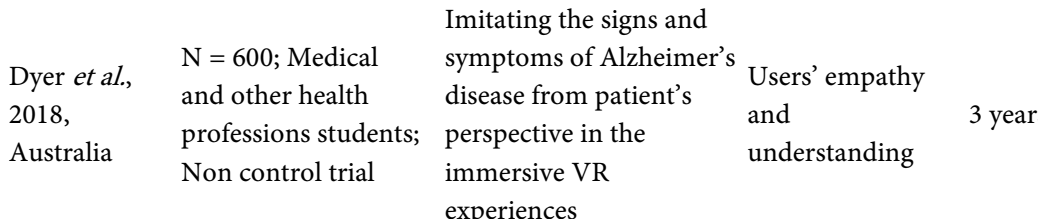

VR simulation experience enhanced students' understanding of age-related health problems and increased their empathy for older adults with vision and hearing loss or Alzheimer's disease.

experiences

$\begin{array}{ll}\text { Kidd } & \mathrm{N}=126 ; \text { Mental } \\ \text { et al., } & \text { Nursing students; } \\ \text { 2012, } & \text { Non control study; } \\ \text { Israel } & \text { Quantitative design }\end{array}$

Simulating student nurse and patient avatars

Nursing students' interviews in VR skills; mental environment of Second status assessment NA

Life ${ }^{\circledast}$ Simulation for mental health assessments communication.
The research results suggested that Virtual reality simulations in online worlds such as Second Life ${ }^{\infty}$ can be used to teach nursing students skills such as mental status assessment and communication.

\begin{tabular}{|c|c|c|c|c|c|}
\hline $\begin{array}{l}\text { Formosa } \\
\text { et al., 2017, } \\
\text { Australia }\end{array}$ & $\begin{array}{l}\mathrm{N}=50 ; \text { General } \\
\text { public and various } \\
\text { psychology } \\
\text { undergraduate; Non } \\
\text { control study; } \\
\text { Quantitative design }\end{array}$ & $\begin{array}{l}\text { Imitating the signs and } \\
\text { symptoms of psychosis } \\
\text { from patient's perspective } \\
\text { in the immersive VR } \\
\text { experiences }\end{array}$ & $\begin{array}{l}\text { Users' knowledge, } \\
\text { attitudes, and } \\
\text { empathy }\end{array}$ & NA & $\begin{array}{l}\text { Participants' scores were significantly enhanced } \\
\text { at post-test across each outcome measure, with } \\
\text { significant correlations found between a number } \\
\text { of the gain and user-experience scores ( } \mathrm{p} \leq \\
0.001 \text { ). }\end{array}$ \\
\hline $\begin{array}{l}\text { Passig et al., } \\
2011, \text { Israel }\end{array}$ & $\begin{array}{l}\text { Experimental group } \\
(\mathrm{N}=40) \text {, Control } \\
\text { group }(\mathrm{N}=40) ; \\
\text { Teachers; Controlled } \\
\text { trial; Mixed study } \\
\text { design }\end{array}$ & $\begin{array}{l}\text { Imitating the signs and } \\
\text { symptoms of dyslexia } \\
\text { from patient's perspective } \\
\text { in the immersive VR } \\
\text { experiences }\end{array}$ & $\begin{array}{l}\text { Users' knowledge } \\
\text { and awareness of } \\
\text { dyslexia }\end{array}$ & NA & $\begin{array}{l}\text { The research results suggested that experiencing } \\
\text { a variety of simulated types of dyslexia by VR can } \\
\text { bring about a greater improvement in teacher } \\
\text { awareness of the dyslexic pupil's cognitive } \\
\text { experiences than is achieved by viewing a film } \\
\text { about dyslexia ( } \mathrm{p} \leq 0.001) \text {. }\end{array}$ \\
\hline $\begin{array}{l}\text { Jütten et al., } \\
2018, \\
\text { Netherlands }\end{array}$ & $\begin{array}{l}\text { Intervention group } \\
(\mathrm{N}=145) \text {, Control } \\
\text { group }(\mathrm{N}=56) ; \\
\text { Informal caregivers } \\
\text { for people with } \\
\text { dementia; } \\
\text { Longitudinal } \\
\text { controlled trial; } \\
\text { Mixed study design }\end{array}$ & $\begin{array}{l}\text { Imitating the signs and } \\
\text { symptoms of dementia } \\
\text { from patient's perspective } \\
\text { in the immersive VR } \\
\text { dementia simulator } \\
\text { training }\end{array}$ & $\begin{array}{l}\text { Empathy, } \\
\text { Caregiver's sense } \\
\text { of competence, } \\
\text { understanding } \\
\text { of disease }\end{array}$ & 15 months & $\begin{array}{l}\text { No significant differences were found between } \\
\text { the two groups over time regarding empathy } \\
\text { ( } \mathrm{p} \leq 0.862 \text { ), sense of competence ( } \mathrm{p} \leq 0.47 \text { ). } \\
\text { For the participants who underwent the training, } \\
\text { the understanding of dementia was enhanced } \\
\text { and almost all caregivers indicated that they had } \\
\text { learned something from the training. }\end{array}$ \\
\hline
\end{tabular}

Contrary to the findings of a positive relationship between VR simulation and empathy gain in the aforementioned studies, Jütten and colleagues [37] found no significant differences $(\mathrm{p}=0.862)$ between the two. The study recruited 201 informal caregivers for people with dementia and 145 participants who were as- 
signed to the intervention group to the experience of dementia-like symptoms in a VR simulation. They suggested that a lack of educational features such as including role playing and accompanying feedback of VR simulation could have contributed to the negative result.

\subsection{Users' Attitude Alteration}

Stigmatized attitudes and beliefs towards mental illness can be in the form of social stigma [42]. While health professional is a member of the general public, stigma towards clients can be found in various studies [43] [44] [45]. Cashwell [46] suggested that mental health related training professionals can have less stigmatizing attitudes than non-mental-health professionals. Changing negative attitude and stigma of either general public or medical professionals towards mental illness is vital as stigma significantly hindered the recovery of mental illness [47].

Two studies [37] [39] have discussed the VR simulation impact on users' attitude and both have shown a positive relationship between VR simulation and improvement on understanding and stigmatization. Both of them conducted the study on a non-healthcare population.

Jütten and colleagues [37] found that the dementia patient's informal caregivers who underwent their VR simulation have heightened their understanding of the disease which was beneficial for both the caregivers and patients. Almost all caregivers in the study indicated that they changed the way they cared for the dementia patients and became more effective caregivers after the VR simulation. Jütten and colleagues suggested that a better understanding can lead to a better relationship with and enhanced well-being of the patients with fewer communication problems. Consistent with the study conducted by Formosa and colleagues [39], participants' scores on the area of fear and exclusion, understanding and tolerance, and community integration were significantly increased in the attitude posttest $(\mathrm{p}<0.001)$.

Taken social desirability response bias into account, Jütten and colleagues [37] argued that the positive attitude of the caregivers was valued over the change on empathy.

\subsection{Users' Knowledge Enhancement}

The users' knowledge gain was seen having the greatest research interests among researchers studying the impacts of VR simulation on medical education of mental illness as all of the selected articles have measured users' knowledge as part of their research outcome. As the Canadian Alliance on Mental Illness and Mental Health emphasizes the importance of mental health literacy in the recognition [48], management or prevention of mental health problems, enhancing users' knowledge on mental illness has a potential benefit on medical education.

There are five selected articles which examined users' knowledge and all of the articles [34] [35] [36] [38] [39] have the unanimous conclusion on the relation- 
ship between VR simulation and the improvement in awareness of disease, symptom identification and skill competence. Three of them assessed VR simulation as a teaching strategy in health profession students [34] [35] [36].

Sweigart and colleagues [34] have found significant improvement among student nurses using a psychiatric assessment tool $(\mathrm{p}=0.001)$ after they experienced virtual dialogs with patient avatars in the virtual clinic constructed in the world of Second Life. Students with no virtual interview experience had a lower average score on questions assessed during an interview compared to those who had interviewed a patient avatar in a virtual environment. The data supported the efficacy of VR simulation on the transference of skills to practice on students. It is in line with Kidd and colleagues' [35] study that adopted VR simulation in mental status assessment and communication with patients among undergraduate mental health nursing students. The 126 mental nursing students indicated the benefits of VR simulation as allowing students to learn communication and health assessment skills in a stress-free environment where mistakes would not lead to catastrophic outcomes. Dyer [36] also found health profession students demonstrating an increased understanding for older adults who have Alzheimer's disease.

Passig and colleagues [38] attributed the effectiveness of VR simulation on enhancing users' knowledge to its capability in transforming an experience hard to illustrate verbally into a virtual visible scenario. Formosa and colleagues [39] also suggested similar findings in their study that while there is no overt ways of teaching diagnostic technique of schizophrenic symptoms via VR simulation, learners can still benefit from content-based knowledge.

\section{Discussions}

This literature review summed up up-to-date evidence about the current use of VR simulation in education among students of health professionals relating to mental illness on improving users' empathy, attitude and knowledge. The sound effectiveness of the VR simulation on mental health education on improving users' empathy, attitude and knowledge were shown in this review. Of note, only three studies assessed the usage of VR simulation in training health profession students, while three other studies evaluated the effectiveness of the technology in raising awareness and understanding of mental disorders among the general population. There is also a noteworthy difference between the effect of VR simulation on primary participants with a healthcare background and the comparison group of participants with a non-healthcare background. Unlike the other two studies [36] [39] that involved medical and other health professions students and psychology undergraduates who eventually experience unanimously positive impacts on their empathy, the comparison group made up of non-healthcare background participants studied by Jütten and colleagues [37] was the only research that found no empathetic improvement on its participants. Healthcare education aims to develop competent and inquiring professionals 
who perform roles of preventing, treating and curing diseases and of promoting health at both the individual and societal levels. The specific learning needs are explicitly different to that of the general population. Despite an encouraging effect of VR simulation in general mental health education, the effectiveness of VR simulation on health profession student specifically remains unclear. Nevertheless, our findings are in line with a systematic review [49] which suggested that learning empathy through simulation is an appropriate teaching tool for health professional students. This review also found varying impacts of effectiveness on the VR simulation on the empathy of users with a healthcare background and those without.

Improvement on learners' knowledge and attitude is the most significant findings as all selected articles pointed to the unanimous result. However, the technology's improvement on learners' empathy remains disputable among the selected articles. The authors in the only study that concluded a negative relationship between the two [37] suggested that their results might be susceptible to VR simulation content that was unfit to the users' needs and hence resulted in the unchanged empathy. Meanwhile, the results from the remaining two studies which showed positive improvement on empathy are still valid. The significance of the impact on users' empathy and attitude echoes the hypothesis of Kolb's Experiential Learning Theory that experiential learning can generate empathy and positive attitude [50] [51] [52]. While acquisition and retention of knowledge can be generated by instructional materials [53] [54], the potential of experiential learning via VR simulation is huge in mental health education.

In spite of encouraging benefits of VR simulation in mental health education, there have not yet been sufficient and conclusive evidence to promise these benevolent impacts on students of the health industry, as conclusions were mainly drawn from participants without healthcare background. The results were also undermined by the methodological variation of the reviewed studies, various quality of the controlled and the small number of included studies $(n=6)$. In addition, there was a lack of consensus on the simulation training protocol and elements of simulation training in mental health education. The long term benefits and whether the simulated experience is transferable to real-life practice remain uncertain. In summary, results have supported the feasibility and effectiveness of VR simulation in equipping health profession students in mental health training. More research is needed to explore the greatest value of VR simulation in health profession education.

Despite the aforementioned advantages of VR simulation, participant age and technical difficulty could be the concerns of the effectiveness of the VR simulation (Table 2). While Kidd and colleagues [35] found no correlations were found between participant age and perceived educational VR simulation effectiveness, Formosa and colleagues [39] revealed the significant inverse relationship between age and fidelity, immersion, and user buy-in in VR simulation. Although the motivation of some older adult to adopt and use technologies is 
Table 2. Summary of advantages and disadvantages of VR simulation.

\begin{tabular}{|c|c|}
\hline Advantages & Disadvantages \\
\hline \multicolumn{2}{|c|}{ Greater ecologically valid stimulus presentation Participant age limitation } \\
\hline $\begin{array}{l}\text { Tighter control of } 3 \mathrm{D} \text { simulated } \\
\text { environment }\end{array}$ & $\begin{array}{l}\text { Unpleasant Users experience including nausea } \\
\text { and dizziness }\end{array}$ \\
\hline Higher manipulative virtual environments & Staff training and time issue \\
\hline $\begin{array}{l}\text { Hazard-free simulated environment } \\
\text { allowing limitless }\end{array}$ & High installation and developer fee \\
\hline
\end{tabular}

low [55], study suggests older people could as well as younger people be taught to use technology if longer time is given [56]. While the study conducted by Jütten and colleagues [37] has a mean age of 63.8 in intervention group, positive result in enhancing users' attitude could still be found in the study. The adoption of VR simulation should be restricted by the users' age. Besides, Kidd and colleagues [35] identified the relationship between the educational effectiveness and technical difficulty encountered by the users. Dyer and colleagues [36] suggested the limitation of VR would be the staff training for troubleshooting the technology when problems arise.

\section{Limitations}

This review has several limitations. First, this review includes and analyzes published articles only while grey or unpublished articles are not included, which may lead to publication bias [57] in the analysis. Second, restricting the language of analysis to English only may lead to the omission of relevant studies. Third, the inclusion criteria in this review were relatively broad, including various study designs and a high variation of participants, which may have contributed to our findings of non-conclusive results.

\section{Conclusions and Future Research}

This literature review sought to determine the effectiveness of virtual reality-based simulation in medical education to enhance users' knowledge, attitudes, and empathy relating to mental Illness. Findings suggest that there is a clear relationship between VR simulation and improvement on users' empathy, attitude and knowledge relating to mental Illness. With the unique characteristic of experiential learning of VR simulation, there is a potential development of VR simulation on empathy and attitude in mental health education. Also, users with healthcare background may experience greater impacts of VR simulation on their empathy. Yet, the availability of existing studies on the adoption of VR simulation in mental health education is still limited. In the future, with current review and preliminary result on the effectiveness of VR simulation on mental health education, randomized controlled trial study with a larger sample size could be done to examine its effectiveness on a wider range of mental illnesses such as depression and general anxiety disorder. 


\section{Acknowledgements}

The project described was supported by the Teaching Development and Language Enhancement Grant, The University of Hong Kong, Award Number (Project no. 18/683). The content is solely the responsibility of the authors and does not necessarily represent the official views of the funding organizations.

\section{Conflicts of Interest}

The authors declare no conflicts of interest regarding the publication of this paper.

\section{References}

[1] Freina, L. and Ott, M. (2015) A Literature Review on Immersive Virtual Reality in Education: State of the Art and Perspectives.

[2] Heilig, M.L. (1962) Sensorama Simulator. Google Patents.

[3] Macpherson, C. and Keppell, M.J. (1998) Virtual Reality: What Is the State of Play in Education? Australasian Journal of Educational Technology, 14, 60-74. https://doi.org/10.14742/ajet.1929

[4] Mantovani, F., et al. (2003) Virtual Reality Training for Health-Care Professionals. CyberPsychology \& Behavior, 6, 389-395. https://doi.org/10.1089/109493103322278772

[5] Dubovi, I., et al. (2017) Now I Know How! The Learning Process of Medication Administration among Nursing Students with Non-Immersive Desktop Virtual Reality Simulation. Computers \& Education, 113, 16-27. https://doi.org/10.1016/j.compedu.2017.05.009

[6] Anthes, C., et al. (2016) State of the Art of Virtual Reality Technology. Aerospace Conference, Big Sky, 5-12 March 2016. https://ieeexplore.ieee.org/document/7500674 https://doi.org/10.1109/AERO.2016.7500674

[7] Harrison, G.W., Haruvy, E. and Rutström, E.E. (2011) Remarks on Virtual World and Virtual Reality Experiments. Southern Economic Journal, 78, 87-94. https://doi.org/10.4284/0038-4038-78.1.87

[8] Jensen, L., Konradsen, F.J.E. and Technologies, I. (2018) A Review of the Use of Virtual Reality Head-Mounted Displays in Education and Training. Education and Information Technologies, 23, 1515-1529.

https://doi.org/10.1007/s10639-017-9676-0

[9] Johnson, L., et al. (2016) NMC Horizon Report: 2016 Higher Education Edition. The New Media Consortium.

[10] Brunero, S., Jeon, Y.H. and Foster, K. (2012) Mental Health Education Programmes for Generalist Health Professionals: An Integrative Review. International Journal of Mental Health Nursing, 21, 428-444. https://doi.org/10.1111/j.1447-0349.2011.00802.x

[11] Aruna, G., et al. (2016) Perception, Knowledge, and Attitude toward Mental Disorders and Psychiatry among Medical Undergraduates in Karnataka: A Cross-Sectional Study. Indian Journal of Psychiatry, 58, 70-76. https://doi.org/10.4103/0019-5545.174381

[12] Horsfall, J., Cleary, M. and Hunt, G. (2010) Stigma in Mental Health: Clients and 
Professionals. Issues in Mental Health Nursing, 31, 450-455. https://doi.org/10.3109/01612840903537167

[13] Kolb, D.A., et al. (2001) Experiential Learning Theory: Previous Research and New Directions. Perspectives on Thinking, Learning, and Cognitive Styles, 1, 227-247.

[14] Yardley, S., Teunissen, P.W. and Dornan, T.J. (2012) Experiential Learning: Transforming Theory into Practice. Medical Teacher, 34, 161-164. https://doi.org/10.3109/0142159X.2012.643264

[15] Chmil, J.V., et al. (2015) Effects of an Experiential Learning Simulation Design on Clinical Nursing Judgment Development. Nurse Educator, 40, 228-232. https://doi.org/10.1097/NNE.0000000000000159

[16] Galloway, S.J. (2009) Simulation Techniques to Bridge the Gap between Novice and Competent Healthcare Professionals. Online Journal of Issues in Nursing, 14, Manuscript 3.

http://ojin.nursingworld.org/MainMenuCategories/ANAMarketplace/ANAPeriodic als/OJIN/TableofContents/Vol142009/No2May09/Simulation-Techniques.aspx

[17] Ryall, T., Judd, B.K. and Gordon, C. (2016) Simulation-Based Assessments in Health Professional Education: A Systematic Review. Journal of Multidisciplinary Healthcare, 9, 69-82. https://doi.org/10.2147/JMDH.S92695

[18] Cantrell, M.A., et al. (2017) The Evidence in Simulation-Based Learning Experiences in Nursing Education and Practice: An Umbrella Review. Clinical Simulation in Nursing, 13, 634-667. https://doi.org/10.1016/j.ecns.2017.08.004

[19] Brown, A.M. (2015) Simulation in Undergraduate Mental Health Nursing Education: A Literature Review. Clinical Simulation in Nursing, 11, 445-449. https://doi.org/10.1016/j.ecns.2015.08.003

[20] Akaike, M., et al. (2012) Simulation-Based Medical Education in Clinical Skills Laboratory. The Journal of Medical Investigation, 59, 28-35. https://doi.org/10.2152/jmi.59.28

[21] Cooper, S., et al. (2012) Simulation Based Learning in Midwifery Education: A Systematic Review. Women and Birth, 25, 64-78. https://doi.org/10.1016/j.wombi.2011.03.004

[22] Zendejas, B., et al. (2013) State of the Evidence on Simulation-Based Training for Laparoscopic Surgery: A Systematic Review. Literature Review in Annals of Surgery, 257, 586-593. https://doi.org/10.1097/SLA.0b013e318288c40b

[23] Aebersold, M. (2018) Simulation-Based Learning: No Longer a Novelty in Undergraduate Education. Online Journal of Issues in Nursing, 23, 1.

[24] Zigmont, J.J., Kappus, L.J. and Sudikoff, S.N. (2011) Theoretical Foundations of Learning through Simulation. Seminars in Perinatology, 35, 47-51. https://doi.org/10.1053/j.semperi.2011.01.002

[25] Luctkar-Flude, M., Wilson-Keates, B. and Larocque, M.J. (2012) Evaluating High-Fidelity Human Simulators and Standardized Patients in an Undergraduate Nursing Health Assessment Course. Nurse Education Today, 32, 448-452. https://doi.org/10.1016/j.nedt.2011.04.011

[26] McGaghie, W.C., et al. (2010) A Critical Review of Simulation-Based Medical Education Research: 2003-2009. Literature Review in Medical Education, 44, 50-63. https://doi.org/10.1111/j.1365-2923.2009.03547.x

[27] Wilson, C.J. and Soranzo, A. (2015) The Use of Virtual Reality in Psychology: A Case Study in Visual Perception. Computational and Mathematical Methods in Medicine, 2015, Article ID: 151702. https://doi.org/10.1155/2015/151702 
[28] Giuseppe, R. and Wiederhold, B.K. (2015) The New Dawn of Virtual Reality in Health Care: Medical Simulation and Experiential Interface. Studies in Health Technology and Informatics, 219, 3-6.

[29] Pantelidis, V.S. (1996) Suggestions on When to Use and When Not to Use Virtual Reality in Education. VR in the Schools, 2, 18.

[30] Ando, S., et al. (2011) The Simulation of Hallucinations to Reduce the Stigma of Schizophrenia: A Systematic Review. Schizophrenia Research, 133, 8-16. https://doi.org/10.1016/j.schres.2011.09.011

[31] Christou, C. (2010) Virtual Reality in Education. In: Affective, Interactive and Cognitive Methods for e-Learning Design: Creating an Optimal Education Experience, IGI Global, Hershey, 228-243. https://doi.org/10.4018/978-1-60566-940-3.ch012

[32] Riva, G., et al. (2016) Transforming Experience: The Potential of Augmented Reality and Virtual Reality for Enhancing Personal and Clinical Change. Frontiers in Psychiatry, 7, 164. https://doi.org/10.3389/fpsyt.2016.00164

[33] Cook, J.M., et al. (2010) What Do Psychotherapists Really Do in Practice? An Internet Study of over 2,000 Practitioners. Psychotherapy: Theory, Research, Practice, Training, 47, 260-267. https://doi.org/10.1037/a0019788

[34] Sweigart, L., et al. (2014) Virtual Simulations across Curriculum Prepare Nursing Students for Patient Interviews. Clinical Simulation in Nursing, 10, e139-e145. https://doi.org/10.1016/j.ecns.2013.10.003

[35] Kidd, L.I., et al. (2012) Effectiveness of a Second Life ${ }^{\circledast}$ Simulation as a Teaching Strategy for Undergraduate Mental Health Nursing Students. Journal of Psychosocial Nursing, 50, 28-37. https://doi.org/10.3928/02793695-20120605-04

[36] Dyer, E., et al. (2018) Using Virtual Reality in Medical Education to Teach Empathy. Journal of the Medical Library Association, 106, 498. https://doi.org/10.5195/JMLA.2018.518

[37] Jütten, L.H., et al. (2018) Can the Mixed Virtual Reality Simulator into Dementia Enhance Empathy and Understanding and Decrease Burden in Informal Dementia Caregivers? Dementia and Geriatric Cognitive Disorders Extra, 8, 453-466. https://doi.org/10.1159/000494660

[38] Passig, D. (2011) The Impact of Immersive Virtual Reality on Educator's Awareness of the Cognitive Experiences of Pupils with Dyslexia. Teachers College Record, 113, 181-204.

[39] Formosa, N.J., et al. (2018) Testing the Efficacy of a Virtual Reality-Based Simulation in Enhancing Users' Knowledge, Attitudes, and Empathy Relating to Psychosis. Australian Journal of Psychology, 70, 57-65. https://doi.org/10.1111/ajpy.12167

[40] Preston, S.D. and de Waal, F.B.M. (2002) Empathy: Its Ultimate and Proximate Bases. Behavioral and Brain Sciences, 25, 1-20. https://doi.org/10.1017/S0140525X02000018

[41] Farrow, T.F. and Woodruff, P.W. (2007) Empathy in Mental Illness. Vol. 1, Cambridge University Press, Cambridge. https://doi.org/10.1017/CBO9780511543753

[42] Ahmedani, B.K. (2011) Mental Health Stigma: Society, Individuals, and the Profession. The Journal of Social Work Values and Ethics, 8, 4-1-4-16.

[43] Hansson, L., et al. (2013) Mental Health Professionals' Attitudes towards People with Mental Illness: Do They Differ from Attitudes Held by People with Mental Illness? International Journal of Social Psychiatry, 59, 48-54.

https://doi.org/10.1177/0020764011423176

[44] Serafini, G., et al. (2011) Stigmatization of Schizophrenia as Perceived by Nurses, 
Medical Doctors, Medical Students and Patients. Journal of Psychiatric and Mental Health Nursing, 18, 576-585. https://doi.org/10.1111/j.1365-2850.2011.01706.x

[45] Wahl, O. and Aroesty-Cohen, E.J. (2010) Attitudes of Mental Health Professionals about Mental Illness: A Review of the Recent Literature. Journal of Community Psychology, 38, 49-62. https://doi.org/10.1002/jcop.20351

[46] Smith, A.L. and Cashwell, C.S. (2010) Stigma and Mental Illness: Investigating Attitudes of Mental Health and Non-Mental-Health Professionals and Trainees. The Journal of Humanistic Counseling, Education and Development, 49, 189-202. https://doi.org/10.1002/j.2161-1939.2010.tb00097.x

[47] Wahl, O.F. (2012) Stigma as a Barrier to Recovery from Mental Illness. Trends in Cognitive Sciences, 16, 9-10. https://doi.org/10.1016/j.tics.2011.11.002

[48] Bourget, B. and Chenier, R. (2007) Mental Health Literacy in Canada: Phase One Report Mental Health Literacy Project.

[49] Bearman, M., et al. (2015) Learning Empathy through Simulation: A Systematic Literature Review. Simulation in Healthcare, 10, 308-319. https://doi.org/10.1097/SIH.0000000000000113

[50] Vanlaere, L., Coucke, T. and Gastmans, C. (2010) Experiential Learning of Empathy in a Care-Ethics Lab. Nursing Ethics, 17, 325-336. https://doi.org/10.1177/0969733010361440

[51] Varkey, P., Chutka, D.S. and Lesnick, T.G. (2006) The Aging Game: Improving Medical Students' Attitudes toward Caring for the Elderly. Journal of the American Medical Directors Association, 7, 224-229. https://doi.org/10.1016/j.jamda.2005.07.009

[52] Karlowicz, K.A. and Palmer, K.L. (2006) Engendering Student Empathy for Disabled Clients with Urinary Incontinence through Experiential Learning. Urologic Nursing Journal, 26, 373-378.

[53] Custers, E. (2010) Long-Term Retention of Basic Science Knowledge: A Review Study. Advances in Health Science Education: Theory \& Practice, 15, 109-128. https://doi.org/10.1007/s10459-008-9101-y

[54] Tayyeb, R. (2013) Effectiveness of Problem Based Learning as an Instructional Tool for Acquisition of Content Knowledge and Promotion of Critical Thinking among Medical Students. Journal of College of Physicians and Surgeons Pakistan, 23, 42-46.

[55] Fausset, C.B., et al. (2013) Older Adults' Perceptions and Use of Technology: A Novel Approach. International Conference on Universal Access in Human-Computer Interaction, Las Vegas, 21-26 July 2013, 51-58. https://doi.org/10.1007/978-3-642-39191-0_6

[56] Broady, T., Chan, A. and Caputi, P. (2010) Comparison of Older and Younger Adults' Attitudes towards and Abilities with Computers: Implications for Training and Learning. British Journal of Educational Technology, 41, 473-485. https://doi.org/10.1111/j.1467-8535.2008.00914.x

[57] Easterbrook, P.J., et al. (1991) Publication Bias in Clinical Research. The Lancet, 337, 867-872. https://doi.org/10.1016/0140-6736(91)90201-Y 